\section{University of Warwick: impact of the Library on the research process}

\author{
Chris Bradford
}

\section{The Author}

Chris Bradford is currently the Education Librarian and Social Sciences Team Leader at Warwick University. Prior to this she worked as a subject librarian at Oxford Brookes University and Middlesex University. Initially Chris worked as a teacher in London and continues to be interested in how to apply the psychology of learning to the practice of information retrieval.

\section{Introduction}

The University of Warwick Library has been interested for some time in how librarians can support the research process more actively within their institution.

This research project had three strands:

- To what extent it was viable for librarians to locate/identify specific journals in which academics could publish new articles.

- Whether it was possible to create a hierarchy of publishing opportunity in specific subject areas so that ultimately academics could adapt articles as necessary and place accordingly

- To ascertain whether librarians could position themselves within new "communities of practice" in the area of research support

\section{Importance of the topic to the University of Warwick Library}

Warwick is a research intensive institution and one of the key threads of the Library's current strategic plan is to structure more systematic research support for academics and their departments. Traditionally such support has been offered through research skills training sessions. Academic departments throughout Warwick are keen to maintain or increase their RAE ratings. A further driver was the University emphasis on the development of research skills from the undergraduate level onwards.

In the Social Sciences Departments queries from academics were arising, about how to ascertain the merit of particular journals in which to publish. Some of these queries came from experienced academics, now having to publish in new interdisciplinary areas; others came from academics new to a particular research area. 


\section{Application of the Impact Implementation Methodology}

We adopted an action research methodology. To begin with we conducted semi-structured interviews with academics and researchers to gain a picture of current publishing practice amongst researchers. As we obtained some understanding of the publication process, as well as becoming conversant with the extent of data that could be obtained via Ulrichs, and the insufficient amount of Social Science Impact data that often exists, matching key research themes, it became necessary to adapt our proposed investigation. There were three constraining factors that meant the application of the impact implementation methodology had to evolve as the project progressed.

- The assessment of what constitutes an "excellent" title is subjective and fluid. Some academics maintain that quality journals can not always be located with key word mapping and an underpinning in-depth knowledge of a particular subject area is always needed.

- The area of research support has never been articulated clearly in librarianship and the reticence of many librarians to act as unpaid research assistants has in some areas meant that the whole area of research support, bar post-graduate research skills training, has laid fallow.

- It became evident as the research progressed, that not only does the esteem of a journal fluctuate so do the rules of publication when applied to the prestige of an individual author i.e. important authors can place their work more readily in higher ranked journals. Furthermore some academics do not always wish to place their journals in the 'best' publication, they want to use the journal title which is most appropriate.

Initially we conducted a feasibility study into creating an interdisciplinary journal title database that would include impact data, publication data, editorial panel data, and leadin-time to publication. It was hoped that such a database would provide academics with some sort of hierarchy of publishing opportunity. However given the fluidity and subjectivity of journal data coupled with the time frame that we were operating under, it was decided to continue by promoting the Ulrichs Serials Analysis System in conjunction with the Social Sciences Journal Contents Reports. These tools were subsequently demonstrated at Research Meetings, Research Development Days and to particular groups or individual academics as interested. We also distributed key lists of journals from the JCR and Ulrichs to match individual researchers interests and research centre themes.

One particular group of academics that we encountered were particularly keen on the creation of a mind map of research opportunity that would include mapping significant journal titles with impact data on to research themes. This work is still in progress.

\section{Success Criteria \\ Long term measure}

To compare HERO submissions data for the Institute of Education and CRER (Centre for Research in Ethnic Relations) for the RAE 2001 exercise and for the RAE 2008 exercise.

\section{Short term measure}

Comparing interactions with CRER and Education on research support pre-2003 interventions and after 2003 interventions.

\section{Evidence collected - methods used}

To obtain a picture of current publishing practice amongst researchers we used opportunistic focus groups, semi-structured interviews and conversations. We then collated the number and type of interactions concerning article publishing that arose from both the Institute of Education and CRER.

\section{Significant results}

\section{Publishing practice}

- Lead in time to publication can vary according to the prestige of the individual

- Lead in time to publication can vary according to the date of the RAE

- Some academics consider that it is impossible to construct a list of key journals in a particular research area because the area is too fluid and subjective. 
- Journal status does change and individuals ultimately need to make their own assessment. Trends can be more significant than data relating to individual years.

- In some areas of research e.g. Religious Education - key journals are not assigned impact data and in depth knowledge of the area is critical

- Academics with prestigious research outputs are more sceptical of journal impact data.

- Academics don't always want to publish in journals with the highest quality sometimes they want the title that is most appropriate

- Many new researchers depend on their supervisors recommendations when placing articles

- The word "international" at the start of a journal title can be misleading; the editorial panel and publisher can be more useful.

- It can be difficult to publish within the American market.

\section{Librarian's role}

- Some academics consider that it is impossible to construct a list of key journals in a particular research area because key word searches are too crude, and in-depth knowledge of the research area is always needed

- That a knowledge of journal impact factors is useful to all post-graduates and academic staff - particularly to academic staff new to a particular research area

- It can be considered that citing from journals with high impact can improve the quality of a piece of work therefore JCR should be included in post-graduate training

- Departments that are particularly pressurised to improve their research rating are more likely to be interested in working more closely with impact data than those that are not.

- Academics that are new to a particular research area find impact data useful as a starting point.

- Impact data can be useful within Education in broadening the perspective of particular academics from specialised curriculum areas published in journals with less impact to those of more wider impact.
- The Institute of Education were particularly interested in targeting their publications at journals with high impact data and there were over seventy enquiries relating to impact data from particular academics following the promotion of JCR and Ulrichs. Involvement of the Librarian was also subsequently sought in research away days, professorial staff meetings and in the preparation of one research bid.

\section{How the results have been used}

On-line training with Ulrichs and JCR is now incorporated into the WIRE. (Warwick University's Library on-line research support) Work is still on-going with the Social Science departments. Social Science Librarians now introduce JCR and Ulrich's in all post-graduate training and offer training to new academic staff as necessary.

\section{What was learnt from participation?}

Practitioner based enquiry is very useful at providing opportunity to reflect on existing practice whilst developing new models of intervention. The success of interventions into existing practice, are also determined by the timing and receptivity of particular Department or Research Centre's circumstances. The Institute of Education at Warwick is the only department that scored a 4 in the last RAE. It is critical that it improves its rating at the next one. The adoption of a publishing strategy, targeting articles at journals with high impact has been deemed essential and this intervention has been positively welcomed. Other departments and research centres with scores of 5 in the last RAE have been more ambivalent. The investigation did conclude that academics new to a particular research area and postgraduate students do find knowledge of JCR and Ulrich's helpful in commencing their research. 